\title{
In Situ Temperature Measurement of an Optical Fiber Submitted to Electric Arc Discharges
}

\author{
Gaspar Rego, Luís M. N. B. F. Santos, Bernd Schröder, Paulo V. S. Marques, José L. Santos, and \\ Henrique M. Salgado, Member, IEEE
}

\begin{abstract}
Type $\mathrm{S}$ thermocouples were assembled in situ by applying high intensity electric arc discharges to the contact junction of two platinum (Pt) and Pt-10\% rhodium (Pt-10\% Rh) wires, inserted on a silica capillary. The electrically insulated thermocouples built in this way were afterwards employed to estimate the temperature of an optical fiber subjected to arc discharges. For typical values of the arc discharge parameters used to arc-induce long-period fiber gratings (electric current $I=9 \mathrm{~mA}$ and arc duration $t=1 \mathrm{~s}$ ), a capillary peak temperature value of $1420^{\circ} \mathrm{C} \pm$ $40^{\circ} \mathrm{C}$ was obtained by extrapolation of the experimental data for the limit situation of having a thermocouple with negligible diameter. The temperature profiles in the capillary and in an optical fiber were calculated based on a heat transfer model implemented by a finite element algorithm and fitted to the experimental temperature distribution in the Pt and Pt-10\% Rh wires. The correspondent peak temperatures computed for the capillary and for the fiber were $1450{ }^{\circ} \mathrm{C}$ and $1320{ }^{\circ} \mathrm{C}$, respectively. A good agreement between the capillary temperature values determined graphically and numerically was obtained.
\end{abstract}

Index Terms-Electric arc discharge, long-period fiber gratings (LPFGs), optical fiber components, temperature measurement.

\section{INTRODUCTION}

$\mathbf{L}$ ONG-PERIOD fiber gratings (LPFGs) are periodic structures, typically with periodicities of hundreds of microns, which couple light from guided to cladding modes at specific wavelengths that satisfy the resonance condition [1]. The LPFGs transmission spectra are characterized by dips at particular wavelengths which, in turn, depend on physical parameters such as temperature and pressure. Therefore, these gratings are wavelength-selective tunable filters that find a wide range of applications as optical communications devices [1], [2] and as optical sensors [3]. LPFGs fabricated using the electric arc technique proved already to be an interesting alternative to the devices produced by ultraviolet radiation [4]. However, in what

Manuscript received March 16, 2004; revised May 5, 2004. The work of G. Rego was supported by a grant from the Program PRODEP III. The work of B. Schröder was supported by a postdoctoral scholarship (BPD 35131/2000).

G. Rego is with Unidade de Optoelctrónica e Sistemas Electrónicos do INESC-Porto, 4169-007 Porto, Portugal, and also with the Escola Superior de Tecnologia e Gestão-IPVC, 4900-348 Viana do Castelo, Portugal (e-mail: gmr@hobbit.fc.up.pt).

P. V. S. Marques and J. L. Santos are with Unidade de Optoelctrónica e Sistemas Electrónicos do INESC-Porto, 4169-007 Porto, Portugal, and also with the Department de Física, FCUP, 4169-007 Porto, Portugal.

H. M. Salgado is with Unidade de Optoelctrónica e Sistemas Electrónicos do INESC-Porto, 4169-007 Porto, Portugal, and also with the Department Engineering Electrotécnica e de Computadores, FEUP, 4200-465 Porto, Portugal.

L. M. N. B. F. Santos and B. Schröder are with the Departamento de Química, Centro de Investigação em Química, Faculdade de Ciencias da Universidade do Porto, 4169-007 Porto, Portugal.

Digital Object Identifier 10.1109/LPT.2004.831559 concerns arc-induced gratings, the mechanisms responsible for their formation are still under investigation. In this context, the temperature reached by the fiber during the electric arc discharge is an important parameter to be considered. Moreover, the electric current of the arc discharges depends on the electrodes configuration and on their degradation, hence, the temperature could be used instead to control adequately the fabrication conditions of these structures.

In this letter, we present a method based on the use of Type $S$ thermocouples assembled in situ to evaluate the temperature of the fiber while being heated by electric arc discharges.

\section{EXPERIMENTAL RESULTS}

In order to determine the temperature of an optical fiber during an electric arc discharge, several steps were performed. The first step consisted on the assembling of electrically shielded Type $\mathrm{S}$ thermocouples (platinum $(\mathrm{Pt})$ wire and $\mathrm{Pt}-10 \%$ rhodium (Rh) alloy provided by Goodfellow) using wires with diameters of 25 and $50 \mu \mathrm{m}$ in four distinct configurations: $25 / 25$, $50 / 50,25 / 50$, and 50/25. To assemble in situ the Type $\mathrm{S}$ thermocouples, a cleaved silica capillary $\left(D_{\text {in }} / D_{\text {out }}=56 / 125 \mu \mathrm{m}\right)$ was fixed on the reference v-groove of the BICC fusion splicing machine. A straight Pt wire was placed on the other v-groove, with $x-y-z$ position control. Actuating on the micrometer controller, the wire was introduced about $20 \mathrm{~mm}$ inside the capillary. Afterwards, the whole process was repeated for the Pt-10\% Rh alloy until physical contact of the wires occurred inside the capillary. After centering the region to be fused with the electrodes of the splicing machine (the gap between electrodes is $1.0 \mathrm{~mm}$ and the electrode apex angle is $40^{\circ}$ ), an electric arc discharge $(I>15 \mathrm{~mA})$ was applied while pushing the wires against each other.

Following the thermocouple assembly, the electric current was reduced to $9 \mathrm{~mA}$ and arc discharges of 3-s duration were applied in different axial positions of the wires. The voltage in the thermocouples was measured with a computer controlled multimeter (Fig. 1). The process dynamics, for the 50- $\mu \mathrm{m}$ thermocouple, during the heating and cooling down is shown in Fig. 2. It can be seen that the system reaches the thermal stationary equilibrium in less than $1 \mathrm{~s}$. This holds for all thermocouples used independently of the axial position and of the electric current values $(I<15 \mathrm{~mA})$. Fig. 3 shows the temperature distribution in the 25- and 50- $\mu \mathrm{m}$ thermocouples, obtained by applying arc discharges in steps of tenths to hundreds of micrometers for about $5 \mathrm{~mm}$ on both sides of the thermocouple junction. For each position, the equilibrium voltage was registered and it was converted to temperature using the reference function for Type 


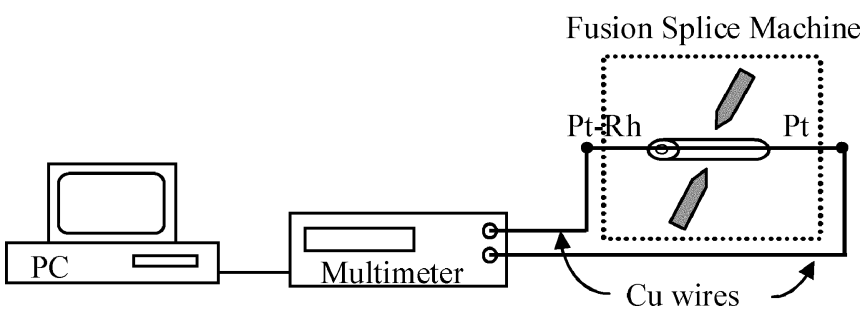

Fig. 1. Experimental setup used to measure the voltage on the thermocouples during the electric arc discharges.

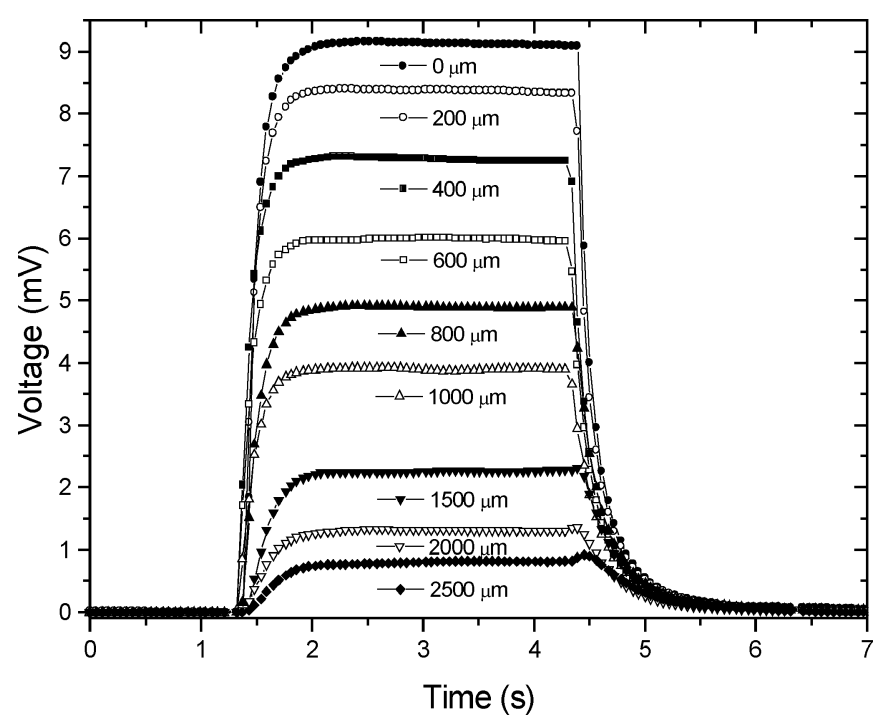

Fig. 2. Time evolution of the voltage in the 50- $\mu \mathrm{m}$ thermocouple for discharges produced at several axial positions on the Pt-10\% Rh wire.

S thermocouples based on the ITS-90 [5]. A region of about 150-200 $\mu \mathrm{m}$ around the thermocouple junction presents an almost constant temperature, which may correspond to the dimensions of the central zone of the arc-discharges (Fig. 3).

The peak temperature of the capillary was obtained assuming that as the energy dissipated through the wires approaches zero, the thermocouple temperature would approach the capillary temperature without thermocouple. The energy dissipated through the wires was calculated using the averaged value of the temperature gradients in the vicinity of each thermocouple junction and assuming the same thermal conductivity for both wires, regarding the high temperatures to be measured. Fig. 4 shows the temperature in the thermocouples junction obtained for the three different diameters used. The error bars account for the uncertainty in the thermocouples diameter $( \pm 1 \mu \mathrm{m})$ and the uncertainty in their positioning between the electrodes which, in turn, affects the temperature measurement $\left( \pm 10^{\circ} \mathrm{C}\right)$. The linear fitting applied to the experimental data, points toward a capillary temperature of approximately $1420^{\circ} \mathrm{C}$ with an overall uncertainty of $\pm 40^{\circ} \mathrm{C}$.

The temperature profile in the capillary was derived through the measurements of the temperature profiles in the thermocouples. A simplified heat transfer model of the assembly based on a finite element analysis, assuming a heat source of reduced dimensions, was fitted to the temperature distribution in the thermocouples. Radial heat transfer was simulated by a finite element method using a commercial partial differentiation solver

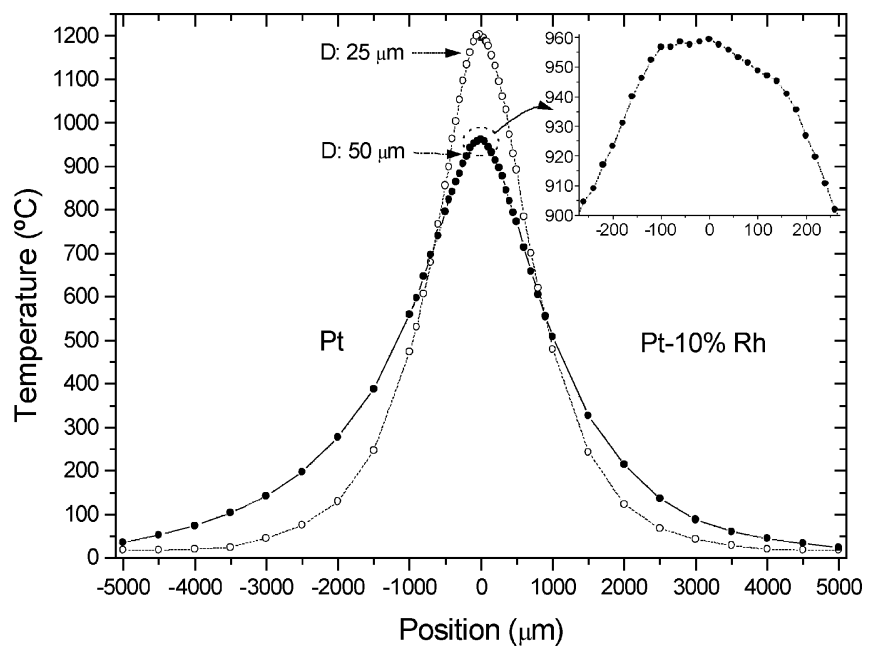

Fig. 3. Temperature distribution in the 25- and 50- $\mu \mathrm{m}$ Type $\mathrm{S}$ thermocouples. Inset: temperature distribution around the junction of the $50-\mu \mathrm{m}$ Type $\mathrm{S}$ thermocouple.

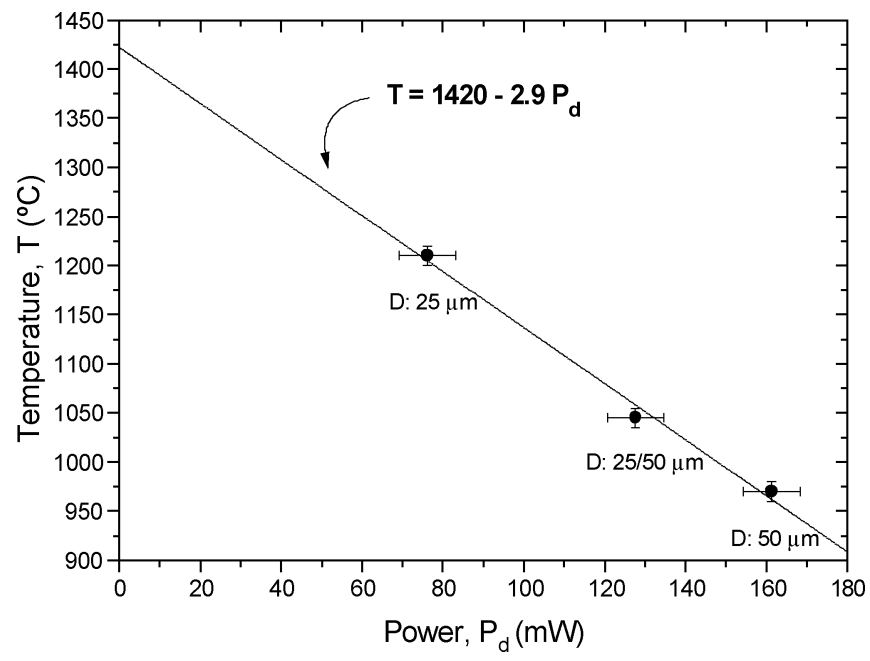

Fig. 4. Peak temperature versus power dissipated through the thermocouples.

(Flex PDE 2.13 from PDE Solutions, Inc), using a two-dimensional steady state conduction model, which holds for the period after thermal stationary equilibrium is reached, and neglecting internal radiative heat transfer within the silica capillary. Radiative heat transfer was considered at the surface boundary, along with a convection contribution. The temperature profile in an optical fiber was calculated in a similar way. Fig. 5 shows the estimated temperature profiles in the capillary and in a fiber. The correspondent capillary peak temperature is of about $1450{ }^{\circ} \mathrm{C}$, in good agreement with the value obtained from Fig. 4. The fiber peak temperature value of approximately $1320{ }^{\circ} \mathrm{C}$ also agrees well with the estimated value determined using another method which relies on the blackbody radiation [6]. The temperature value reported by Mohanna [7], for a discharge of $9 \mathrm{~mA}$, is about $200{ }^{\circ} \mathrm{C}$ higher. However, the comparison cannot be easily done since crucial data, such as the electrodes gap, was not given. The dependence on temperature of the parameters involved in the above calculations and related to Pt, silica, and air was taken from literature [8], [9]. 




Fig. 5. Temperature profiles in the capillary (with and without thermocouples inside) and in the fiber computed by finite element analysis.

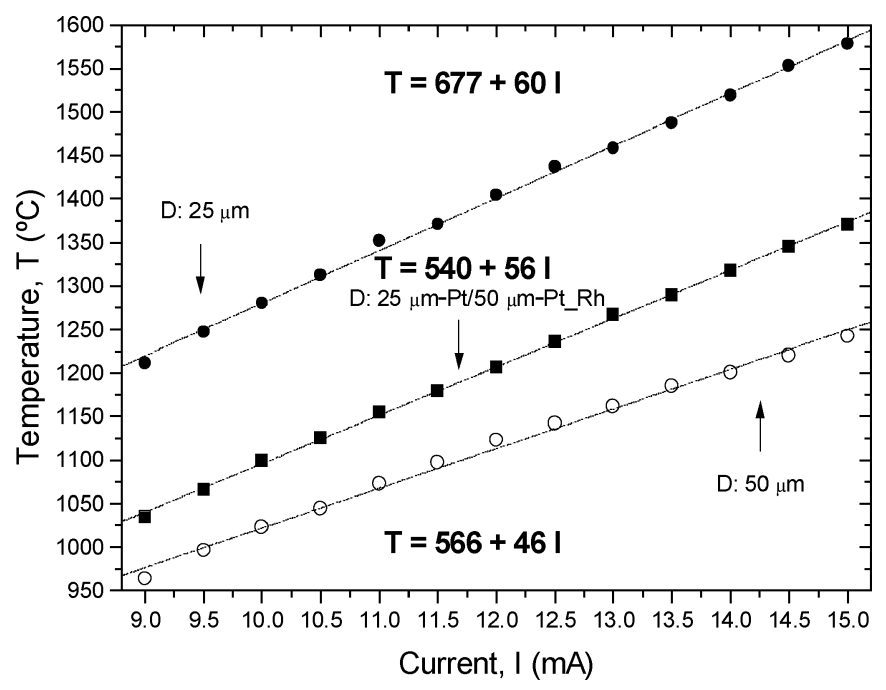

Fig. 6. Peak temperature versus electric current for the various thermocouples used.

The dependence of the peak temperature on the electric current was also investigated. Arc discharges with electric currents between 9 and $15 \mathrm{~mA}$ were applied to the thermocouples junction. As shown in Fig. 6, a linear dependence between the peak temperature and the electric current of the arc discharge was found for all thermocouples. Considering the temperature value of $1320{ }^{\circ} \mathrm{C}$ obtained for an electric current of $9 \mathrm{~mA}$ and assuming a slope of $60^{\circ} \mathrm{C} / \mathrm{mA}$ (this underestimated value corresponds to the slope of the $25-\mu \mathrm{m}$ thermocouple, however, regarding the dependence of the slopes on the thermocouples diameters shown in Fig. 6, it should be, nevertheless, close to the real value), a fiber temperature close to $2000{ }^{\circ} \mathrm{C}$ would be expected for an electric current of $20 \mathrm{~mA}$. This temperature value matches the one obtained using a microradiation thermometer [10].

\section{CONCLUSION}

We have presented a new technique based on electrically insulated thermocouples to measure the temperature of an optical fiber while being heated through electric arc discharges. The thermocouples were assembled in situ by applying high current arc discharges $(15-18 \mathrm{~mA}, 1 \mathrm{~s})$ to the wires in physical contact, placed previously inside a silica capillary. The following discharges with lower currents (9-15 mA) and performed at different axial positions produced a temperature profile in the wires. For a current of $9 \mathrm{~mA}$, a capillary temperature of $1420{ }^{\circ} \mathrm{C} \pm 40{ }^{\circ} \mathrm{C}$ was obtained by extrapolation of the experimental data for near-zero diameter thermocouples. The temperature profiles in the capillary and in the optical fiber were determined by solving the classical heat transfer equations making use of the data obtained for the thermocouples with different diameters. The respective peak temperatures calculated for the fiber (capillary) was of about $1320^{\circ} \mathrm{C}\left(1450^{\circ} \mathrm{C}\right)$. The fiber temperature values agree well with those obtained using other techniques [6], [10]. This method allows the measurement of an important parameter, the fiber temperature under electrical arc discharges, that concerns not only the control of the LPFGs fabrication process, but also the mechanisms responsible for their formation.

\section{ACKNOWLEDGMENT}

The authors would like to thank ACREO for supplying the capillary, and M. C. Torres for technical support.

\section{REFERENCES}

[1] A. M. Vengsarkar, P. J. Lemaire, J. B. Judkins, V. Bhatia, T. Erdogan, and J. E. Sipe, "Long-period fiber gratings as band-rejection filters," $J$. Lightwave Technol., vol. 14, pp. 58-65, Jan. 1996.

[2] Y. J. Rao, T. Zhu, Z. L. Ran, Y. P. Wang, J. Jiang, and A. Z. Hu, "Novel long-period fiber gratings written by high-frequency $\mathrm{CO}_{2}$ laser pulses and applications in optical fiber communications," Opt. Commun., vol 229, pp. 209-221, Jan. 2004.

[3] S. W. James and R. P. Tatam, "Optical fiber long-period grating sensors: characteristics and application," Meas. Sci. Technol., vol. 19, pp. 49-61, Mar. 2003.

[4] G. Rego, O. Okhotnikov, E. Dianov, and V. Soulimov, "High temperature stability of long-period fiber gratings produced using an electric arc," J. Lightwave Technol., vol. 19, pp. 1574-1579, Oct. 2001.

[5] G. W. Burns, M. G. Scroges, G. F. Strouse, M. L. Croarkin, and W. F. Guthrie, "Temperature-Electromotive Force Reference Functions and Tables for the Letter-Designated Thermocouple Types Based on the ITS90," in NIST Monograph 175, 1993.

[6] G. Rego, P. V. S. Marques, H. M. Salgado, and J. L. Santos, "Measurement of the temperature of an optical fiber submitted to an electric arc discharge," in Proc. SPIE, vol. 5502, J. M. Lopez-Higuera and B. Culshaw, Eds., June 2004, pp. 374-377.

[7] Y. Mohanna, "Electric arc temperature estimation of a fiber splicer," Proc. Inst. Elect. Eng.-Optoelectron., vol. 142, pp. 313-315, Dec. 1995.

[8] Y. S. Touloukian and C. Y. Ho, Thermophysical Properties of Matter: The TPRC Data Series. Plenum, N.Y.: Purdue Univ., 1970.

[9] A. J. C. Grellier, "Characterization of optical fiber tapering using a $\mathrm{CO}_{2}$ laser," Ph.D. thesis, Kent Univ., Canterbury, U.K, July 2000.

[10] I. Hatakeyama and H. Tsuchiya, "Fusion splices for single-mode optical fibers," IEEE J. Quantum Electron., vol. QE-14, pp. 614-619, Aug. 1978. 